\title{
CHEMICAL MODIFICATIONS OF A CYSTEINYL RESIDUE INTRODUCED IN THE BINDING SITE OF CARBOXYPEPTIDASE Y BY SITE-DIRECTED MUTAGENESIS
}

\author{
by
}

\author{
LENE M. BECH and KLAUS BREDDAM
}

Department of Chemistry, Carlsberg Laboratory

Gamle Carlsberg Vej 10, DK-2500 Copenhagen Valby

\begin{abstract}
Keywords: Carboxypeptidase Y, protein engineering, site-directed mutagenesis, chemical modifications, peptide synthesis, deamidations
\end{abstract}

It is demonstrated that site-directed mutagenesis successfully can be combined with chemical modification creating enzyme derivatives with altered properties. A methionyl residue located in the $S_{1}$ binding site of carboxypeptidase $Y$ was replaced by a cysteinyl residue and the mutant enzyme was isolated and modified with various alkylating and thioalkylating reagents. Treatment of the mutant carboxypeptidase $Y$ with bulky reagents like phenacyl bromide and benzyl methanethiolsulfonate caused a drastic reduction in the activity towards substrates with bulky leaving groups in the $\mathrm{P}_{1}^{\prime}$ position, i.e. $-\mathrm{OBzl},-\mathrm{Val}-\mathrm{NH}_{2}$ and amino acids (except $-\mathrm{Gly}-\mathrm{OH}$ ), while substrates with small groups in that position, i.e. - OMe and $-\mathrm{NH}_{2}$, were hydrolysed with increased rates. The presence of a positive charge, in addition to a bulky group, had a further adverse effect on the activity towards substrates with large leaving groups, whereas the activity towards those with small leaving groups remained unaffected by such a group. The derivatives obtained by modification of the mutant enzyme with benzyl methanethiolsulfonate and methyl methanethiolsulfonate were effective in deamidations of peptide amides and peptide synthesis reactions, respectively.

Abbreviations: AeMTS = aminoethyl methanethiolsulfonate; AeS-Cys-CPD-Y = Cys-CPD-Y modified with AeMTS; Ama-Met-CPD-Y = CPD-Y modified with iodoacetamide; Arg-CPD-Y = CPD-Y with an arginyl residue at position 398; BzlMTS = benzyl methanethiolsulfonate; BzlS-Cys-CPD-Y = Cys-CPD-Y modified with BzlMTS; Eta-Cys-CPD-Y = Cys-CPD-Y modified with 1-bromo-2-butanone; Bz = N-benzoyl; Bzl = benzyl; CPD-Y = carboxypeptidase Y; Cys-CPD-Y = CPD-Y with a cysteinyl residue at position 398; EDTA = ethylene diamine tetraacetic acid, sodium salt; FA = furylacryloyl; Hepes = N-2-hydroxyethylpiperazine-N'-2-ethane sulfonic acid; HPLC = high performance liquid chromatography; Mes = 2-(N-morpholino) ethane sulfonic acid; MeMTS = methyl methanethiolsulfonate; MeS-Cys-CPD-Y = Cys-CPD-Y modified with MeMTS; Pha-Cys-CPD-Y = Cys-CPD-Y modified with phenacyl bromide; Pha-Met-CPD-Y = CPD-Y modified with phenacyl bromide; PrMTS = propyl methanethiolsulfonate; PrS-Cys-CPD-Y = Cys-CPD-Y modified with PrMTS; SDS = sodium dodecylsulfate; $Z$ = N-carbobenzoxy. Abbreviations of peptides are according to guidelines of IUPAC-IUB Commission on Biochemical Nomenclature. The binding site notation for the enzymes is that of SCHECHTER and BERGER (17). Accordingly, the binding site for the C-terminal amino acid residue is denoted $S_{1}$, and those for the amino acid residues in the amino-terminal direction away from the scissile bond are denoted $S_{1}, S_{2}, \ldots, S_{n}$. Amino acids in the substrate are referred to as $P_{1}, P_{2}, \ldots, P_{n}$ and $P_{1}^{\prime}$ in correspondence with the binding sites. 


\section{INTRODUCTION}

The function of particular amino acid residues in the active site of enzymes has been studied for many years by chemical modifications of functional groups. Another method for elucidation of enzymatic mechanisms, based on the developments during the past 10 years in DNA technology (22), has rendered it possible to specifically exchange amino acids in proteins. This approach is limited to substitutions with the other amino acids. In the present paper chemical modifications and site-directed mutagenesis are combined, thus permitting a large variety of structures to be introduced at an important position in the protein: a methionyl residue, located at position 398 in the $S_{1}^{\prime}$ binding site of carboxypeptidase $Y$ is replaced by a cysteinyl residue, the most reactive side-chain in a protein. After isolation of the mutant enzyme, it is chemically modified with several reagents. The various CPD-Y derivatives are used to elucidate the steric conditions and in addition, the effects of a positive charge in this particular region.

\section{MATERIALS AND METHODS}

\subsection{Materials}

The plasmid pTSY3 containing the PRC1 gene, coding for CPD-Y, and Saccharomyces cerevisiae SEY2202 (MATa $\Delta p r c 1-\Delta l(L E U 2)$ leu2-3 leu3-112 ura3-52 his4-519) were kindly provided by Dr. ToM STEVENS, University of Oregon, USA. The E. coli strain RZ1032 was a generous gift from Dr. Thomas A. KUNKEL, National Institute of Environmental Health Sciences, USA. The E. coli strains JM101 (14) and ED8654 (15) and the M13mp8-derivative G42 (21) were from house collections. Restriction endonucleases, T4 DNA ligase, DNA polymerase I (Klenow fragment), calf intestinal phosphatase, T4 polynucleotide kinase, adenosine triphosphate, M13 sequencing primer 5'-d(TCCCAGTCACGACGT)-3' were obtained from Boehringer Mannheim, FRG. 2'3'-dideoxyribonucleotide triphosphates were obtained from P-L Biochemicals, USA and HPLC purified 2' deoxyribonucleotide triphosphates were from Pharmacia, Sweden. [ $\left.\alpha-{ }^{32} \mathrm{P}\right]$
$\mathrm{dATP}(>800 \mathrm{Ci} / \mathrm{mmol})$ and $\left[\gamma_{-}{ }^{32} \mathrm{P}\right] \mathrm{ATP}(>7000$ $\mathrm{Ci} / \mathrm{mmol}$ ) were from New England Nuclear, USA. Nitrocellulose filters were from Schleicher \& Schuell, FRG. Trizma base, Mes, Hepes, DTT, agarose and L-amino acids were from Sigma, USA. Phenacyl bromide was from Fluka AC, Switzerland, 1-bromo-2-butanone and 2-bromo ethylamine.HBR were from Aldrich, FRG, and MeMTS was from EGA Chemie, FRG. Methane sulfonyl chloride, sodium sulfide, 1-bromo-propan and benzyl bromide were from Merck, FRG and Z-Ala-Ser$\mathrm{NH}_{2}$ was from Vega Biochemicals, USA. FA$\mathrm{Phe}-\mathrm{OMe}, \mathrm{H}-\mathrm{Gly}-\mathrm{NH}_{2}$ and $\mathrm{H}-\mathrm{Val}-\mathrm{NH}_{2}$ were from Bachem, Switzerland, and the following compounds were synthesized as previously described: FA-Phe-Val- $\mathrm{NH}_{2}$, FA-Phe- $\mathrm{NH}_{2}$, FAPhe-Gly-NH $\mathrm{N}_{2}$, FA-Ala-OBzl, FA-Phe-Leu-OH, FA-Phe-Phe-OH, FA-Phe-Val-OH, FA-Phe-Gly$\mathrm{OH}$, FA-Phe-Ala-OH, Bz-Ala-Ala- $\mathrm{NH}_{2}$, Bz-AlaIle- $\mathrm{NH}_{2}$ and $\mathrm{Bz}-\mathrm{Phe}-\mathrm{His}-\mathrm{NH}_{2}(2,5,7)$. The synthetic oligonucleotide was synthesized on an Applied Biosystem 380 DNA synthesizer according to the procedures provided by the manufacturer. PrMTS, BzlMTS and AeMTS were all synthezised from a common precursor, sodium methanethiolsulfonate, prepared by the reaction of methane sulfonyl chloride and sodium sulfide as described by SHAKED et al. (19). Sodium methanethiolsulfonate was reacted with 1-bromopropane (19), benzyl bromide (11) and 2-bromoethyl amine $\cdot \mathrm{HBr}$ (11) to yield PrMTS, BzlMTS and AeMTS, respectively. All other chemicals and solvents were of analytical purity.

\subsection{Methods}

\subsubsection{Preparation of mutant CPD-Y}

Cloning procedures and in vitro mutagenesis were carried out essentially as described in ref. 21 , with the exception that a uracil containing template, prepared as described by KUNKEL (13) was used.

Cys-CPD-Y was isolated and purified as described for wildtype CPD-Y (12). The purification was monitored by assay towards $0.2 \mathrm{mM}$ FA-Phe-Leu-OH as described in ref. 7. The purity of the resulting enzyme $(55 \mathrm{mg}$ ) was ascertained by SDS polyacrylamide gel elec- 
trophoresis on $1 \mathrm{~mm}$ thick $7.5 \%$ gel slabs in an SDS-phosphate continuous buffer system.

\subsubsection{Chemical modification of Cys-CPD-Y}

Modifications of Cys-CPD-Y with MeMTS, PrMTS, BzlMTS and AeMTS were performed in $0.05 \mathrm{M}-\mathrm{NaH}_{2} \mathrm{PO}_{4}, \mathrm{pH} 7.5$ using an enzyme concentration of $5 \mathrm{mg} / \mathrm{ml}$ and a reagent concentration of $0.5 \mathrm{mM}, 0.5 \mathrm{mM}, 3.5 \mathrm{mM}$ and $2.5 \mathrm{mM}$, respectively. Modifications of Cys-CPD-Y with phenacyl bromide and 1-bromo-2-butanon were carried out in $0.03 \mathrm{M}-\mathrm{NaH}_{2} \mathrm{PO}_{4}, 0.12 \mathrm{M}$ $\mathrm{NaCl} \mathrm{pH} 6.5$ using a reagent concentration of $0.5 \mathrm{~mm}$ and $15 \mathrm{~mm}$, respectively. The reactions were followed until the activities remained constant and addition of another aliquot of reagent had no effects. The reactions were terminated by separating enzyme from reagent by gel filtration on Biogel P-4, equilibrated with water. The bed volume was $20-30$ fold the volume of the sample applied. The modified preparations of CysCPD-Y were stored frozen in water at $-18^{\circ} \mathrm{C}$.

\subsubsection{Characterization of $C y s-C P D-Y$ and its derivatives}

The content of free cysteine was determined by titration with para-hydroxymercuribenzoate in the absence of denaturing agents as previously described (16) and the amino acid composition was determined after acid hydrolysis for 24 $\mathrm{h}$ using a Durrum D500 amino acid analyser.

The thermal stability of the enzyme derivatives was investigated by incubation in $50 \mathrm{~mm}-$ Mes, 1 mm-EDTA, pH 6.5 at $55^{\circ} \mathrm{C}$. The activities towards FA-Phe-OMe were followed as a function of time, and assays were performed in 50 mM-Hepes, 1 mM-EDTA, pH 7.5. The stabilities at pH 10.0 were measured by incubating the enzymes at $25^{\circ} \mathrm{C}$ in $50 \mathrm{mM}$-cyclohexylaminopropane sulfonic acid, 1 mM-EDTA, pH 10.0. The activities towards FA-Phe-OMe were followed as a function of time, and the assays were performed in the same buffer as the incubations.

The kinetic constants for the hydrolysis of various FA-ester and peptide substrates by unmodified Cys-CPD-Y and its derivatives were determined from Lineweaver-Burk plots. Such determinations were not possible with peptide amides due to their low solubility combined with high $K_{m}$ values. With these substrates only $k_{\text {cat }} / K_{m}$ was determined by following the hydrolysis to completion at a single concentration of substrate and using the integrated form of the Michaelis Menten equation. Hydrolysis rates were determined spectrophotometrically at 329 $358 \mathrm{~nm}$ and $25{ }^{\circ} \mathrm{C}$. Peptide substrates were assayed in $0.05 \mathrm{M}$-Mes, $1 \mathrm{mM}-\mathrm{EDTA}, \mathrm{pH} 6.5$ whereas ester and amide substrates were assayed in $0.05 \mathrm{M}$-Hepes, $1 \mathrm{mM}$-EDTA, $\mathrm{pH}$ 7.5.

\subsubsection{Peptide synthesis and deamidation of peptide amides}

Peptide synthesis reactions were performed in a pH stat using $0.5 \mathrm{~mm}-\mathrm{FA}-\mathrm{Phe}$-OMe as substrate in the presence of 5 mM-EDTA. With $\mathrm{H}-\mathrm{Gly}-\mathrm{NH}_{2}$ and $\mathrm{H}-\mathrm{Val}-\mathrm{NH}_{2}$ as nucleophiles the experiments were performed at $\mathrm{pH} 7.5$, whereas the experiments with free amino acids as nucleophiles were carried out at $\mathrm{pH} 9.5$. The reactions were followed by HPLC, utilizing a C-18 reverse phase column and other equipment from Waters, and they were allowed to proceed until $80-95 \%$ of the substrate had been consumed. The eluant system comprised $0.1 \%$ TFA as the $A$ buffer and $90 \% \mathrm{CH}_{3} \mathrm{CN}, 0.1 \%$ TFA as the B buffer and various linear and concave gradients were employed. The fraction of aminolysis was expressed as the ratio of the formed aminolysis product to the sum of all product being formed, i.e. unconsumed substrate was disregarded in the calculations. Deamidation reactions were performed at $2 \mathrm{~mm}$-substrate concentration in $10 \% \mathrm{~N}, \mathrm{~N}$-dimethylformamide, 2 mM-EDTA, $\mathrm{pH}$ 8-10 using a $\mathrm{pH}$ stat, and the following eluant system was used: $50 \mathrm{~mm}$-triethylammonium phosphate pH 3.0 (A buffer) and 50 mM-triethylammonium phosphate $\mathrm{pH} 3.0$ in $50 \% \mathrm{CH}_{3} \mathrm{CN}$ (B buffer). The reactions were allowed to proceed for 80 minutes (Bz-Ala-Phe$\mathrm{NH}_{2}$ ), 120 minutes (Bz-Ala-Ala- $\mathrm{NH}_{2}$ ), $115 \mathrm{~min}$ utes (Bz-Ala-Ile- $\mathrm{NH}_{2}$ ) and 180 minutes (Z-AlaSer- $\mathrm{NH}_{2}$ ) using enzyme concentrations of 1.5 $\mu \mathrm{M}, 4 \mu \mathrm{M}, 4 \mu \mathrm{M}$, and $2 \mu \mathrm{M}$, respectively. All separations were carried out at room temperature and monitored at $254 \mathrm{~nm}$ or $302 \mathrm{~nm}$. 
Table I. Kinetic parameters for the hydrolysis of peptide substrates with Met-CPD-Y (wt), Cys-, MeS-Cys-, PrS-Cys-, BzlS-Cys-, AeS-Cys-, Eta-Cys-, and Pha-Cys-CPD-Y.

\begin{tabular}{|c|c|c|c|c|}
\hline Substrate & Enzyme & $\begin{array}{l}\mathbf{k}_{\mathrm{cat}} \\
\left(\mathrm{min}^{-1}\right)\end{array}$ & $\begin{array}{l}\mathrm{K}_{\mathrm{m}} \\
(\mathrm{mM})\end{array}$ & $\begin{array}{l}\mathrm{k}_{\mathrm{cad}} / \mathrm{K}_{\mathrm{m}} \\
\left(\mathrm{min}^{-1} \cdot \mathrm{mM}^{-1}\right)\end{array}$ \\
\hline \multirow[t]{8}{*}{ FA-Phe-Gly-OH } & Met-CPD-Y (wt) & 5800 & 5.4 & 1100 \\
\hline & Cys-CrD-1 & & & \\
\hline & MeS-Cys-CPD-Y & 990 & 4.5 & 220 \\
\hline & PrS-Cys-CPD-Y & 19000 & 11 & 1700 \\
\hline & BzIS-Cys-CPD-Y & 9500 & 13 & 730 \\
\hline & AeS-Cys-CPD-Y & 560 & 33 & 17 \\
\hline & Eta-Cys-CPD-Y & 5200 & 13 & 400 \\
\hline & Pha-Cys-CPD-Y & 950 & 0.86 & 1100 \\
\hline \multirow[t]{8}{*}{ FA-Phe-Ala-OH } & Met-CPD-Y (wt) & 9700 & 0.14 & 70000 \\
\hline & Cys-CPD-Y & 3300 & 0.91 & 3600 \\
\hline & MeS-Cys-CPD-Y & 4800 & 0.31 & 16000 \\
\hline & PrS-Cys-CPD-Y & 5200 & 0.27 & 19000 \\
\hline & BzIS-Cys-CPD-Y & 990 & 0.43 & 2300 \\
\hline & AeS-Cys-CPD-Y & 340 & 0.36 & 940 \\
\hline & Eta-Cys-CPD-Y & 3000 & 0.50 & 6000 \\
\hline & Pha-Cys-CPD-Y & 1100 & 0.25 & 4400 \\
\hline \multirow[t]{8}{*}{ FA-Phe-Val-OH } & Met-CPD-Y (wt) & 6500 & 0.047 & 140000 \\
\hline & Cys-CPD-Y & 5300 & 0.13 & 41000 \\
\hline & MeS-Cys-CPD-Y & 6300 & 0.12 & 53000 \\
\hline & PrS-Cys-CPD-Y & 1600 & 0.056 & 29000 \\
\hline & BzlS-Cys-CPD-Y & 230 & 0.070 & 3300 \\
\hline & AeS-Cys-CPD-Y & 610 & 0.14 & 4400 \\
\hline & Eta-Cys-CPD-Y & 1300 & 0.083 & 16000 \\
\hline & Pha-Cys-CPD-Y & 570 & 0.11 & 5200 \\
\hline \multirow[t]{8}{*}{ FA-Phe-Leu-OH } & Met-CPD-Y (wt) & 4900 & 0.021 & 230000 \\
\hline & Cys-CPD-Y & 1300 & 0.025 & 52000 \\
\hline & MeS-Cys-CPD-Y & 1400 & 0.017 & 82000 \\
\hline & PrS-Cys-CPD-Y & 1600 & 0.028 & 57000 \\
\hline & BzlS-Cys-CPD-Y & 95 & 0.039 & 2400 \\
\hline & AeS-Cys-CPD-Y & 140 & 0.021 & 6700 \\
\hline & Eta-Cys-CPD-Y & 1100 & 0.053 & 21000 \\
\hline & Pha-Cys-CPD-Y & 200 & 0.017 & 12000 \\
\hline \multirow[t]{8}{*}{ FA-Phe-Phe-OH } & Met-CPD-Y (wt) & 5800 & 0.016 & 360000 \\
\hline & Cys-CPD-Y & 3200 & 0.047 & 68000 \\
\hline & MeS-Cys-CPD-Y & 3200 & 0.071 & 45000 \\
\hline & PrS-Cys-CPD-Y & 1500 & 0.064 & 23000 \\
\hline & BzlS-Cys-CPD-Y & 25 & 0.057 & 440 \\
\hline & AeS-Cys-CPD-Y & 520 & 0.036 & 14000 \\
\hline & Eta-Cys-CPD-Y & 620 & 0.097 & 6400 \\
\hline & Pha-Cys-CPD-Y & 290 & 0.017 & 17000 \\
\hline
\end{tabular}

Assay conditions as described in section 2.2.3. 
Table II. Kinetic parameters for the hydrolysis of ester and amide substrates with Met-CPD-Y, Cys-, MeS-Cys-, PrS-Cys-, BzlS-Cys-, AeS-Cys-, Eta-Cys- and Pha-Cys-CPD-Y.

\begin{tabular}{|c|c|c|c|c|}
\hline Substrate & Enzyme & $\begin{array}{l}k_{\text {cat }} \\
\left(\min ^{-1}\right)\end{array}$ & $\begin{array}{l}\mathrm{K}_{\mathrm{m}} \\
(\mathrm{mM})\end{array}$ & $\begin{array}{l}\mathbf{k}_{\mathrm{ca}} / \mathrm{K}_{\mathrm{m}} \\
\left(\mathrm{min}^{-1} \cdot \mathrm{mM}^{-1}\right)\end{array}$ \\
\hline \multirow[t]{8}{*}{ FA-Phe-OMe } & Met-CPD-Y (wt) & 11000 & 0.39 & 28000 \\
\hline & Cys-CPD-Y & 2800 & 0.35 & 8000 \\
\hline & MeS-Cys-CPD-Y & 4700 & 0.34 & 14000 \\
\hline & PrS-Cys-CPD-Y & 12000 & 0.21 & 57000 \\
\hline & BzlS-Cys-CPD-Y & 18000 & 0.17 & 110000 \\
\hline & AeS-Cys-CPD-Y & 4400 & 0.56 & 7900 \\
\hline & Eta-Cys-CPD-Y & 6100 & 0.21 & 29000 \\
\hline & Pha-Cys-CPD-Y & 12000 & 0.19 & 63000 \\
\hline \multirow[t]{8}{*}{ FA-Ala-OBzl } & Met-CPD-Y (wt) & 9100 & 0.054 & 170000 \\
\hline & Cys-CPD-Y & 9100 & 0.039 & 230000 \\
\hline & MeS-Cys-CPD-Y & 6000 & 0.036 & 170000 \\
\hline & PrS-Cys-CPD-Y & 9300 & 0.091 & 100000 \\
\hline & BzIS-Cys-CPD-Y & 12000 & 1.2 & 10000 \\
\hline & AeS-Cys-CPD-Y & 1000 & 0.12 & 8300 \\
\hline & Eta-Cys-CPD-Y & 4200 & 0.22 & 19000 \\
\hline & Pha-Cys-CPD-Y & 4900 & 0.19 & 26000 \\
\hline \multirow[t]{8}{*}{ FA-Phe-NH ${ }_{2}$} & Met-CPD-Y (wt) & & & 89 \\
\hline & Cys-CPD-Y & & & 45 \\
\hline & MeS-Cys-CPD-Y & & & 63 \\
\hline & PrS-Cys-CPD-Y & & & 150 \\
\hline & BzlS-Cys-CPD-Y & & & 610 \\
\hline & AeS-Cys-CPD-Y & & & 16 \\
\hline & Eta-Cys-CPD-Y & & & 130 \\
\hline & Pha-Cys-CPD-Y & & & 240 \\
\hline \multirow[t]{8}{*}{ FA-Phe-Gly-NH } & Met-CPD-Y (wt) & & & 160 \\
\hline & Cys-CPD-Y & & & 130 \\
\hline & MeS-Cys-CPD-Y & & & 140 \\
\hline & PrS-Cys-CPD-Y & & & 400 \\
\hline & BzlS-Cys-CPD-Y & & & 160 \\
\hline & AeS-Cys-CPD-Y & & & 16 \\
\hline & Eta-Cys-CPD-Y & & & 160 \\
\hline & Pha-Cys-CPD-Y & & & 300 \\
\hline \multirow[t]{8}{*}{ FA-Phe-Val-NH ${ }_{2}$} & Met-CPD-Y $(w t)$ & & & 5000 \\
\hline & Cys-CPD-Y & & & 2200 \\
\hline & MeS-Cys-CPD-Y & & & 1300 \\
\hline & PrS-Cys-CPD-Y & & & 280 \\
\hline & BzlS-Cys-CPD-Y & & & 260 \\
\hline & AeS-Cys-CPD-Y & & & 280 \\
\hline & Eta-Cys-CPD-Y & & & 330 \\
\hline & Pha-Cys-CPD-Y & & & 500 \\
\hline
\end{tabular}

Assay conditions as described in section 2.2.3. 


\section{RESULTS}

\subsection{Formation and characterization of Cys-CPD-Y}

The Met-398 to Cys-398 mutation in CPD-Y was accomplished by standard procedures using uracil containing ssDNA prepared from a M13mp8 derivative (21) grown on RZ1032 (13) and a 22-mer oligonucleotide of the sequence 5'-dGGTGGCCACTGTGTTCCATTTG-3'. A mutant phage was identified by dot blot hybridization, and the presence of the mutation was confirmed by chain-termination sequencing. Replicative form DNA was prepared from the mutant phage, and the mutated sequence was reintroduced in the $\mathrm{E}$. coli/yeast shuttle vector pTSY3, replacing the original wildtype sequence. A plasmid containing the mutation was identified and used to transform $S$. cerevisiae strain SEY2202, which contains a deletion in the PRC1 gene, coding for CPD-Y. Plasmid-bearing yeast cells were grown to saturation in a synthetic complete medium free of uracil. Cys-CPD-Y was isolated by affinity chromatography, and SDS gel electrophoresis indicated that the enzyme was homogenous with a molecular weight identical to that of CPD-Y (64000). Titration with para-hydroxymercuribenzoate revealed that Cys-CPD-Y contains 2.0 unblocked cysteinyl residues, while the value for wildtype CPD-Y is 1.0 free cysteinyl residue.

Since the amino acid occupying position 398 is part of the $S_{1}$ binding site $(8,9)$ Cys-CPD-Y was characterized kinetically using a series of FA-ester, FA-peptide and FA-amide substrates with different groups in the $P_{i}^{\prime}$ position. Exchange of Met-398 with a cysteinyl residue resulted in a reduction in $k_{\text {cat }} / K_{m}$ for all the substrates listed in Table I and II (with the exception of FA-Ala-OBzl) due to decreased $k_{\text {cat }}$ values and increased $K_{m}$ values. The increases in $\mathrm{K}_{\mathrm{m}}$ values were most pronounced for peptide substrates with small leaving groups, i.e. Gly$\mathrm{OH}$ and Ala-OH. In the case of FA-Ala-OBzl with the bulky -OBzl leaving group $k_{\text {cat }}$ was of the same order of magnitude as that obtained with CPD-Y (Table II), but $\mathrm{K}_{\mathrm{m}}$ was reduced to about $70 \%$ with this substrate and consequently $\mathrm{k}_{\mathrm{cat}} / \mathrm{K}_{\mathrm{m}}$ was increased.

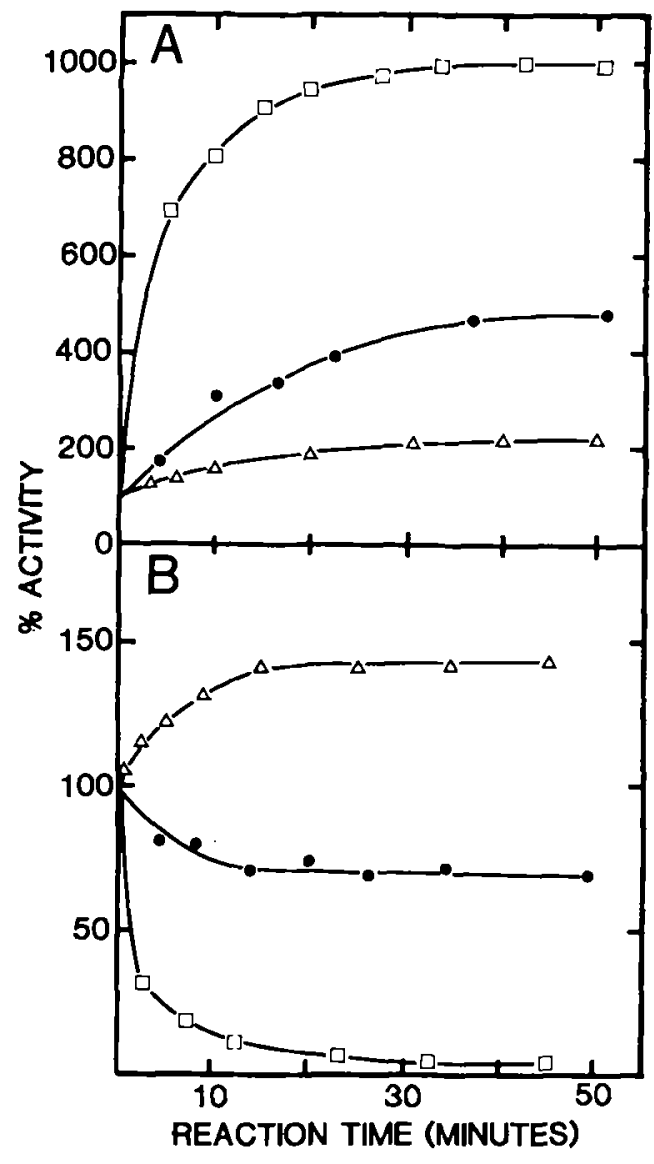

Figure 1. Modification of Cys-CPD-Y with MeMTS, PrMTS, and BzlMTS. The activities of the enzyme towards FA-Phe-OMe (Panel A) and FA-Phe-Leu-OH (Panel B) were assayed during the reaction. Reaction conditions: $5 \mathrm{mg} / \mathrm{ml}$ Cys-CPD-Y, $0.05 \mathrm{M}-\mathrm{NaH}_{2} \mathrm{PO}_{4}$, $\mathrm{pH}$ 7.5. In addition, the reaction mixture contained 0.5 mM-MeMTS $(\Delta), 3.5 \mathrm{~mm}-P+M T S(\bullet)$ or $2.5 \mathrm{~mm}-$ BzlMTS (口).

\subsection{Chemical modification of Cys-CPD-Y}

The influence of various alkylating and thioalkylating reagents on the activity of CysCPD-Y towards FA-Phe-OMe (Figure 1A) and FA-Phe-Leu-OH (Figure 1B) was investigated. With three thioalkylating reagents, BzlMTS, PrMTS and MeMTS, the reactions were complete within one hour. The final activities depended on the bulkiness of the reagent: with BzIMTS, PrMTS and MeMTS, listed in order of 
decreasing molecular volume, the final activities towards FA-Phe-OMe were $1000 \%, 480 \%$ and $220 \%$, respectively, while those towards FA-PheLeu-OH were $6 \%, 74 \%$ and $140 \%$, respectively. Cys-CPD-Y reacted less rapidly with the thioalkylating reagent, AeMTS, presumably because the hydrophobic $S_{1}^{3}$ binding site is quite inaccessible to a positively charged reagent. However within 3 hours the reaction had proceeded to completion and the esterase and peptidase activities had decreased to $70 \%$ and $7 \%$, respectively (data not shown).

Cys-CPD-Y was also modified with two alkylating reagents and also in this case the final activities as measured after 6 hours, depended on the bulkiness of the reagent: With the bulky phenacyl bromide and the less bulky 1-bromo2-butanon the activity towards FA-Phe-Leu-OH had decreased to $20 \%$ and $75 \%$, respectively, and those towards FA-Phe-OMe had increased to $550 \%$ and $300 \%$, respectively.

The amino acid compositions of all the modified enzymes were identical with that of unmodified Cys-CPD-Y. Treatment of the preparations of modified enzyme with para-hydroxymercuribenzoate showed that each derivative contained 1.0 sulfhydryl group, i.e. a decrease of 1.0 relative to the unmodified Cys-CPD-Y.

\subsection{Kinetic characterization of Cys-CPD-Y derivatives}

The alkylated and thioalkylated derivatives of Cys-CPD-Y were characterized kinetically using the same series of substrates as used for characterization of Cys-CPD-Y (Tables I and II). Relative to wildtype CPD-Y, BzlS-Cys-CPD-Y containing the bulky BzlS-group at position 398 hydrolyzed FA-Phe-Gly-OH with increased $\mathrm{k}_{\text {cat }}$ and $\mathrm{K}_{\mathrm{m}}$, while $\mathrm{k}_{\text {cat }} / \mathrm{K}_{\mathrm{m}}$ was slightly reduced (Table I). Pha-Cys-CPD-Y also contains a bulky group and hydrolyzed FA-Phe-Gly-OH with reduced $k_{c a t}$ and $K_{m}$ and unchanged $k_{c a t} / K_{m}$. Peptide substrates with larger leaving groups were hydrolyzed with very low $\mathrm{k}_{\mathrm{cat}} / \mathrm{K}_{\mathrm{m}}$ by both these enzyme derivatives, primarily due to low $k_{\text {cat }}$ values and only to a lesser extent to increased $K_{m}$ values.

The activities of Pha-Cys-CPD-Y and BzlSCys-CPD-Y towards substrates with blocked
C-terminal were drastically affected by the size of the leaving group (Table II). The ester substrate FA-Phe-OMe, which contains a small leaving group, was hydrolyzed by both enzymes with increased $k_{\text {cal }} / K_{m}$ values, relative to unmodified CPD-Y, and this increase was mostly due to low $\mathrm{K}_{\mathrm{m}}$ values. In contrast, FA-Ala-OBzl, which contains a bulky leaving group, was hydrolyzed with reduced $k_{\text {cal }} / K_{m}$ values, primarily due to increased $K_{m}$ values. With peptide amide substrates a similar dependence on the size of the leaving group was observed (Table II): With both BzlS-Cys-CPD-Y and Pha-Cys-CPD$Y k_{c a t} / K_{m}$ for the release of the non-bulky ammonia from FA-Phe- $\mathrm{NH}_{2}$ and $\mathrm{H}-\mathrm{Gly}-\mathrm{NH}_{2}$ from FA-Phe-Gly- $\mathrm{NH}_{2}$ were either at the level of wildtype CPD-Y or higher, while $k_{\text {cat }} / K_{m}$ for release of the bulky $\mathrm{H}-\mathrm{Val}-\mathrm{NH}_{2}$ from FA-PheVal- $\mathrm{NH}_{2}$ was significantly lower.

Incorporation of PrS-and Eta- at Cys-398 also increased the activity towards substrates with small leaving groups and decreased that towards substrates with bulky leaving groups but in a less pronounced manner as compared with BzlSand Pha-. The hydrolysis of FA-Phe-Gly-OH is an exception; PrS-Cys-CPD-Y hydrolyzed this substrate with a high $k_{\text {cal }} / K_{m}$, due to a very high $\mathrm{k}_{\mathrm{cat}}$ value, while it was hydrolyzed with reduced $\mathrm{k}_{\mathrm{ca}} / \mathrm{K}_{\mathrm{m}}$ by Eta-Cys-CPD-Y, primarily due to a decreased $\mathbf{k}_{\text {cat }}$.

Thioalkylation of Cys-398 with the nonbulky reagent MeMTS produced a structure similar in size to the methionyl residue of the wildtype enzyme. MeS-Cys-CPD-Y hydrolyzed all the substrates in Tables I and II with reduced $\mathrm{k}_{\mathrm{ca}} / \mathrm{K}_{\mathrm{m}}$, for peptide substrates due both to reduced $k_{\text {cat }}$ values and increased $K_{m}$ values, and for ester substrates mostly due to reduced $k_{\text {cat }}$ values.

Thioalkylation with the positively charged reagent AeMTS also produced an enzyme which hydrolyzed all the substrates in Tables I and II with lower $k_{c a t} / K_{m}$ values, as compared with CPD-Y. For substrates with blocked C-terminal this decrease was most pronounced for substrates with bulky leaving groups, while $\mathrm{k}_{\mathrm{cat}} / \mathrm{K}_{\mathrm{m}}$ for hydrolysis of peptide substrates was reduced to less than $5 \%$ regardless of the size of leaving group occupying the $\mathrm{P}_{1}^{\prime}$ position. 
Table III. Stability of CPD-Y and position-398 derivatives.

\begin{tabular}{lcc}
\hline Enzyme & $\begin{array}{l}\mathrm{T}_{1 / 2} \text { at } 25^{\circ} \mathrm{C}, \\
\text { pH } 10.0\end{array}$ & $\begin{array}{l}\mathrm{T}_{1 / 2} \text { at } 55^{\circ} \mathrm{C}, \\
\mathrm{pH} 6.5\end{array}$ \\
\hline Met-CPD-Y (wt) & 40 & 36 \\
Cys-CPD-Y & 24 & 190 \\
MeS-Cys-CPD-Y & 64 & 36 \\
PrS-Cys-CPD-Y & 72 & 48 \\
BzlS-Cys-CPD-Y & 62 & 50 \\
AeS-Cys-CPD-Y & 50 & 40 \\
Eta-Cys-CPD-Y & 52 & 52 \\
Pha-Cys-CPD-Y & 30 & 17 \\
\hline
\end{tabular}

Half lives in minutes of apparent first order inactivations. The inactivations were performed as described in section 2.2 .3

\subsection{Stability of Cys-CPD-Y and the chemical derivatives}

The stabilities of the chemically modified derivatives at $25^{\circ} \mathrm{C}, \mathrm{pH} 10.0$ and at $55^{\circ} \mathrm{C}, \mathrm{pH}$ 6.5 were compared with those of Cys-CPD-Y and native CPD-Y. The inactivations under these conditions were apparent first order reactions characterized by the half-lives listed in Table III. At pH 10.0 Cys-CPD-Y showed decreased stability compared to wildtype enzyme, but all the chemical modifications of Cys-398 increased the stability and, with the exception of the modification with phenacyl bromide, to a level even higher than that observed with CPD$\mathrm{Y}$. At elevated temperature and neutral $\mathrm{pH}$ Cys-CPD-Y was significantly more stable than CPD-Y, i.e. $t_{1} / 2$ was 5 times that of CPD-Y. The chemical derivatives of Cys-CPD-Y were inactivated with half-lives between $50 \%$ and $150 \%$ of that of CPD-Y.

\subsection{Application of derivatives of Cys-CPD-Y in peptide synthesis}

The action of CPD-Y, MeS-Cys-CPD-Y, PrSCys-CPD-Y and BzlS-Cys-CPD-Y on the ester substrate FA-Phe-OMe in the presence of $\mathrm{H}$ Gly- $\mathrm{NH}_{2}$ as added nucleophile resulted in the formation of both FA-Phe-Gly-NH $\mathrm{NH}_{2}$ and FAPhe-OH due to a partitioning of the acyl enzyme
Table IV. Influence of the side-chain structure of amino acids on yields of CPD-Y and MeS-Cys-CPD-Y catalysed peptide synthesis.

\begin{tabular}{lcc}
\hline \multirow{2}{*}{ Nucleophile } & \multicolumn{2}{c}{ Yields, \% } \\
\cline { 2 - 3 } & CPD-Y & MeS-Cys-CPD-Y \\
\hline 3.0 M-H-Gly-OH & 60 & 48 \\
1.5 M-H-Ala-OH & 73 & 77 \\
0.2 M-H-Leu-OH & 21 & 45 \\
0.3 M-H-Phe-OH & 11 & 40 \\
1.95 M-H-Arg-OH & 79 & 73 \\
0.58 M-H-His-OH & 13 & 25 \\
1.5 M-H-Thr-OH & 63 & 68 \\
0.63 M-H-Asn-OH & 17 & 19 \\
\hline
\end{tabular}

FA-Phe-OMe was the common substrate used, and yields are given for the formation of FA-Phe-X-OH. Reaction conditions as described in section 2.2.5

intermediate between an aminolysis reaction and a hydrolysis reaction. In all cases the fraction undergoing aminolysis increased with increasing concentration of nucleophile, but it never exceeded 0.90 (Figure $2 \mathrm{a}$ ). $\mathrm{K}_{\mathrm{N}(\mathrm{app}) \text {, }}$ the concentration of nucleophile required to produce a fraction of aminolysis which is half the maximal fraction of aminolysis, i.e. a measure of the binding of nucleophile to the acyl enzyme intermediate (6), was identical with CPD-Y, MeS-Cys-CPD-Y and PrS-Cys-CPD-Y, while it was significantly higher with BzlS-Cys-CPD-Y. A similar experiment with $\mathrm{H}-\mathrm{Val}-\mathrm{NH}_{2}$ as nucleophile (Figure 2B) revealed that this more bulky nucleophile binds rather weakly to PrS-CysCPD-Y and BzlS-Cys-CPD-Y compared with CPD-Y and MeS-Cys-CPD-Y.

The ability of MeS-Cys-CPD-Y and CPD-Y to catalyze aminolysis reactions with FA-PheOMe and free amino acids as nucleophiles was studied (Table IV). The yields with MeS-CysCPD-Y were in most cases of a magnitude similar to those observed with CPD-Y. However, with Leu-OH, Phe-OH and His-OH the values were significantly higher with MeS-CysCPD-Y.

Relative to CPD-Y, BzlS-Cys-CPD-Y is characterized by high amidase activity and low peptidyl amino acid amide hydrolase- and peptidase activities and consequently, one might 


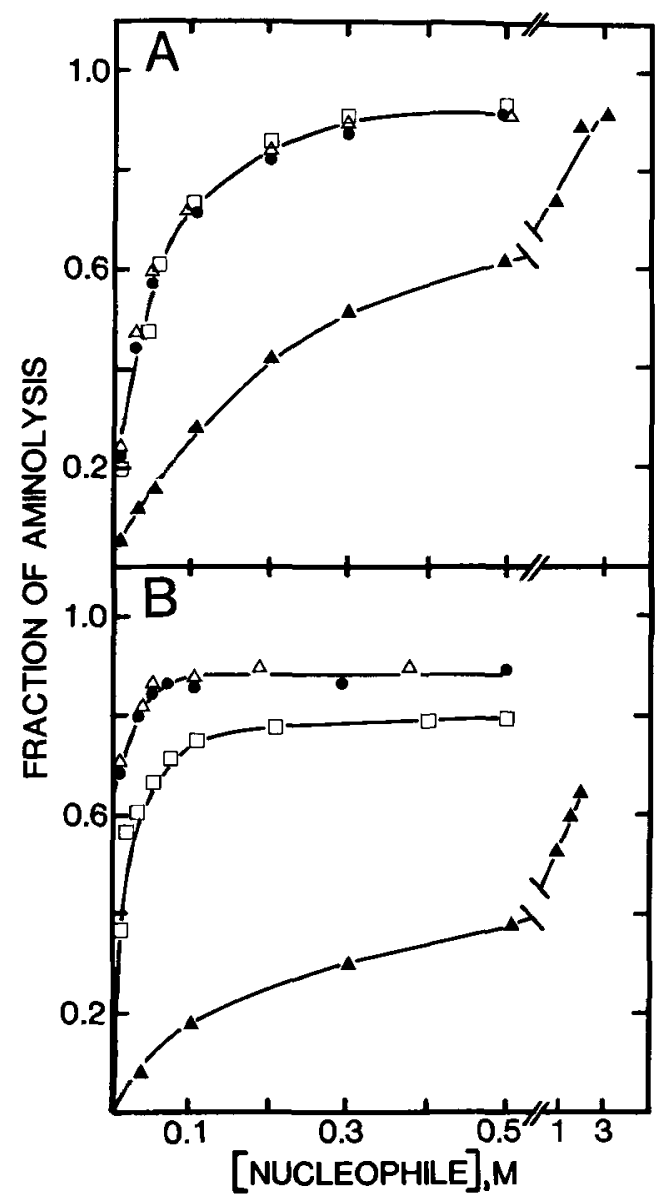

Figure 2. Influence of the concentration of H-Gly$\mathrm{NH}_{2}$ (Panel A) and $\mathrm{H}-\mathrm{Val}-\mathrm{NH}_{2}$ (Panel B) on the fraction of aminolysis in reactions catalysed by $\mathrm{CPD}-\mathrm{Y}$ $(\triangle)$, MeS-Cys-CPD-Y (๑), PrS-Cys-CPD-Y $(\square)$ and BzlS-Cys-CPD-Y (ム) . Reaction conditions: $0.5 \mathrm{~mm}$ FA-Phe-OMe, 5 mM-EDTA and 0.02-0.2 $\mu$ M-CPD-Y,

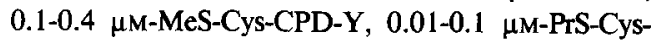
CPD-Y or 0.004-0.2 $\mu \mathrm{M}$-BzlS-Cys-CPD-Y.

expect this enzyme to catalyze the release of ammonia from a peptide amide $\mathrm{Bz}-\mathrm{X}-\mathrm{Y}-\mathrm{NH}_{2}$ ( $\mathrm{X}$ and $\mathrm{Y}=$ amino acid residues), more specifically than CPD-Y with higher yields of deamidation as a result. Since the amidase activity of CPD-Y is known to remain constant at $\mathrm{pH}$ values above 7 , while the peptidase activity decreases at high $\mathrm{pH}$ values (4), deamidation with BzlS-Cys-CPD-Y was investigated at $\mathrm{pH}$ 9.0. In deamidation of $\mathrm{Bz}-\mathrm{X}-\mathrm{Y}-\mathrm{NH}_{2}$ the yield of
$\mathrm{Bz}-\mathrm{X}-\mathrm{Y}-\mathrm{OH}$ was around $96 \%$ using Bz-Phe-Ala$\mathrm{NH}_{2}, \mathrm{Bz}-\mathrm{Ala}$-Ala- $\mathrm{NH}_{2}$, Bz-Ala-Ile- $\mathrm{NH}_{2}$ and BzAla-Phe- $\mathrm{NH}_{2}$ as substrates. The fraction of aminolysis remained constant during the reactions, indicating that the peptide product was not degraded during the reaction. This indicated that BzlS-Cys-CPD-Y, like Pha-Met-CPD-Y (7), is a very specific deamidase. However, with the substrate Z-Ala-Ser- $\mathrm{NH}_{2}$ the yield of deamidation was low due to release of $\mathrm{H}-\mathrm{Ser}-\mathrm{NH}_{2}$, regardless of the enzyme used, i.e. BzlS-CysCPD-Y, Pha-Met-CPD-Y and wildtype CPD-Y.

\section{DISCUSSION}

Both site-directed mutagenesis and chemical modifications can be utilized to produce enzyme derivatives with different catalytic properties, and substitution of the methionyl residue at position 398 of CPD-Y with a reactive cysteinyl residue allowed a combination of these two techniques to be used. The reagents employed in this study do not react with Cys-341 of wildtype CPD-Y or Cys-CPD-Y; this group is only accessible to mercurials (3) and $\mathrm{CNBr}$ (10). Besides, phenacyl bromide has previously been shown to specifically modify Met-398 of wildtype CPD-Y (7), and the thioalkylating agents do not affect the activity of wildtype CPD-Y (unpublished results). Therefore, it was most likely that chemical modification of Cys-398 could be performed specifically; and this was certified by amino acid analysis and titration with parahydroxymercuribenzoate. Several sulfhydryl reagents did not react with Cys-398: iodoacetate, iodoacetamide, acrylonitril and ethylenimine were possibly not sufficiently hydrophobic to bind at the $S_{1}^{\prime}$ binding site, and 5,5'-dithiobis(2nitrobenzoic acid) (Ellmans reagent) was unreactive presumably due to steric hindrance (unpublished results). Iodoacetamide did react with Met-398 in the wildtype enzyme, suggesting that the exchange of Met-398 with a cysteinyl residue alters the structure of the $S_{1}$ binding site such that Cys-398 is more buried and inaccessible as compared with the corresponding methionyl residue of wildtype CPD-Y. This indicates that Cys-398 is more hydrophobic than the corresponding methionyl residue of wildtype CPD$\mathrm{Y}$, consistent with Cys-CPD-Y being more ac- 
Table V. Relative $k_{\text {cat }} / K_{m}$ for CPD-Y and position 398-derivatives normalized to the activity of CPD-Y.

\begin{tabular}{llccccc}
\hline Substrate & CPD-Y & $\begin{array}{l}\text { Pha-Cys- } \\
\text { CPD-Y }\end{array}$ & $\begin{array}{l}\text { Pha-Met- } \\
\text { CPD-Y }\end{array}$ & $\begin{array}{l}\text { AeS-Cys- } \\
\text { CPD-Y }\end{array}$ & $\begin{array}{l}\text { Arg- } \\
\text { CPD-Y }\end{array}$ & $\begin{array}{l}\text { Ama-Met- } \\
\text { CPD-Y }\end{array}$ \\
\hline FA-Phe-OMe & 100 & 230 & 290 & 28 & 12 & 25 \\
FA-Ala-OBzl & 100 & 15 & 1 & 5 & 2 & 6 \\
\hline FA-Phe-NH & 100 & 270 & 250 & 18 & 7 & 19 \\
FA-Phe-Gly-NH & 100 & 190 & 49 & 10 & 27 & 13 \\
FA-Phe-Val-NH 2 & 100 & 10 & 1 & 6 & 4 & 7 \\
\hline FA-Phe-Gly-OH & 100 & 100 & 10 & 2 & 4 & 2 \\
FA-Phe-Ala-OH & 100 & 6 & 1 & 1 & $n . d$. & 0.8 \\
FA-Phe-Val-OH & 100 & 4 & 0.9 & 3 & n.d. & 0.8 \\
FA-Phe-Leu-OH & 100 & 5 & 0.5 & 3 & 0.04 & 0.1 \\
FA-Phe-Phe-OH & 100 & 5 & 1 & 4 & n.d. & n.d. \\
\hline
\end{tabular}

n.d. = not determined

tive towards FA-Ala-OBzl than CPD-Y and the relatively high activity towards FA-Phe-Phe$\mathrm{OH}$. The fact that the four different disulfide forming alkyl alkanethiolsulfonates used in this study react rapidly and specifically with Cys-398 suggest that it will be possible selectively to incorporate a whole family of structures at this important position of the enzyme.

CPD-Y derivatives with positive charges at position 398 have previously been prepared by alkylation of wildtype CPD-Y with iodoacetamide and phenacyl bromide (7), and such chemical modifications all caused drastic reductions in $\mathrm{k}_{\mathrm{cat}}$ for hydrolysis of peptide substrates. Thus, it is possible that the positive charge of the methionyl sulfonium ion is responsible for the low $\mathbf{k}_{\text {cat }}$ values, and this hypothesis has been investigated in the present work. AeS-Cys-CPDY, Arg-CPD-Y (1) and Ama-Met-CPD-Y (7) all contain an aliphatic chain with a positive charge at position 398, and consistent with this they exhibit quite similar activities (Table V). This group of enzyme derivatives is characterized by their low activity towards all substrates, especially the peptide substrates.

Pha-Met-CPD-Y contains a bulky phenyl group in addition to the positive charge, and this enzyme differs from AeS-Cys-CPD-Y, ArgCPD-Y and Ama-Met-CPD-Y by the high rates of release of small leaving groups like methanol and ammonia. The enzyme obtained by treat- ment of Cys-CPD-Y with phenacyl bromide, i.e. Pha-Cys-CPD-Y, is structurally very similar to Pha-Met-CPD-Y but lacks the positive charge (Figure 3), and comparison of the kinetic data of the two enzymes with phenacyl bromide attached shows, that the high activity towards substrates with small leaving groups is essentially independent of the presence of a positive charge. In contrast, the rates of release of bulky groups are lower when a positive charge is present at position 398 in addition to the bulky group. These results suggest that both the sulfonium ion and the phenyl group of the phenacyl bromide modified enzyme are responsible for its low activity towards substrates with large leaving groups, and that the phenyl group alone is responsible for the elevated activities towards substrates with small leaving groups.

The relative $k_{\text {ca }} / K_{m}$ values calculated for each of the derivatives modified at position 398 with FA-Phe-Gly-OH serving as reference, are shown in Table VI. Wildtype CPD-Y has a preference for bulky and hydrophobic leaving groups, especially phenylalanine, and this substrate specificity recurs with the structurally rather similar derivative MeS-Cys-CPD-Y. As the volume of the side chain at position 398 increases, the substrate preference changes so that bulky substrates are no longer strongly preferred. BzlSCys-CPD-Y with the sulfur linked benzyl group (Figure 3) at position 398 is almost equally 


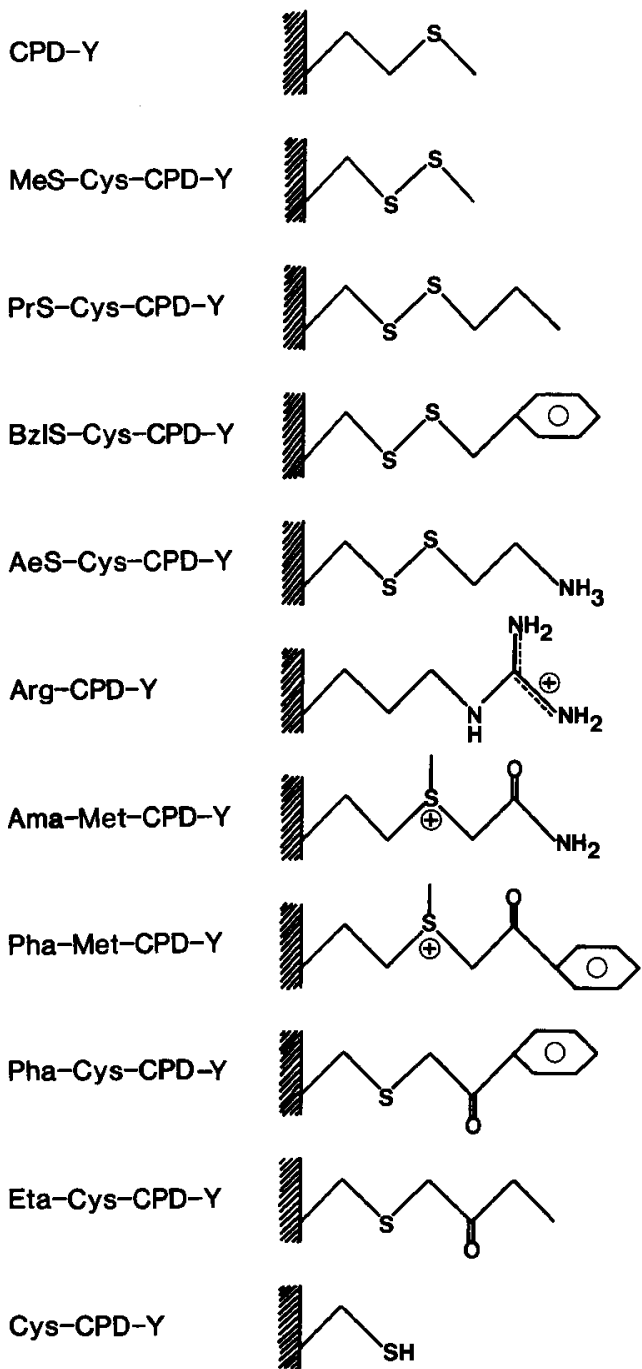

Figure 3. Schematic representation of the structures of the side-chains occupying position 398 in CPD-Y and the derivatives. active towards all the peptide substrates and as the absolute activity towards FA-Phe-Gly-OH is approximately the same as that measured with wildtype CPD-Y, the specificity change is brought about by a drastic reduction in the activity towards substrates with large leaving groups, especially due to very low $k_{\text {cat }}$ values.

The relative $\mathrm{k}_{\mathrm{cat}} / \mathrm{K}_{\mathrm{m}}$ values for hydrolysis of substrates with a blocked C-terminal, with the activity of wildtype CPD-Y serving as a reference, are shown in Table VII. Enzyme derivatives with a bulky group occupying position 398 hydrolyze substrates with small leaving groups (methanol and ammonia) with very high rates while the activity towards substrates with bulky leaving groups is diminished. Thus, it can be concluded that the activity of the enzyme derivatives is affected by the combined size of the group occupying position 398 and the leaving group for all types of substrates.

Due to a drastically altered leaving group specificity, Pha-Met-CPD-Y catalyzes deamidation reactions in much higher yields than CPD$Y(7)$, and since BzlS-Cys-CPD-Y exhibits very high amidase activity and low peptidase activity, this enzyme was also tested as a deamidase. With the peptide amides tested BzlS-Cys-CPD-Y is essentially as specific a deamidase as Pha-MetCPD-Y. However, BzlS-Cys-CPD-Y may be easier to prepare than Pha-Met-CPD-Y due to the rapid and selective modification with BzlMTS.

In aminolysis reactions nucleophiles presumably bind to the $S_{1}^{\prime}$ binding site and consistent with this it appears that there is hardly space for the bulky nucleophile $\mathrm{H}-\mathrm{Val}-\mathrm{NH}_{2}$ in BzISCys-CPD-Y and PrS-Cys-CPD-Y, while this nucleophile can bind tightly to CPD-Y and

Table VI. Relative $k_{c a t} / K_{m}$ for CPD-Y and position-398 derivatives calculated with FA-Phe-Gly as a reference.

\begin{tabular}{lcccccc}
\hline Substrate & CPD-Y & $\begin{array}{l}\text { MeS-Cys- } \\
\text { CPD-Y }\end{array}$ & $\begin{array}{l}\text { Eta-Cys- } \\
\text { CPD-Y }\end{array}$ & $\begin{array}{l}\text { PrS-Cys- } \\
\text { CPD-Y }\end{array}$ & $\begin{array}{l}\text { BzlS-Cys- } \\
\text { CPD-Y }\end{array}$ & $\begin{array}{l}\text { Pha-Cys- } \\
\text { CPD-Y }\end{array}$ \\
\hline FA-Phe-Gly-OH & 1 & 1 & 1 & 1 & 1 & 1 \\
FA-Phe-Ala-OH & 63 & 72 & 15 & 11 & 3 & 4 \\
FA-Phe-Val-OH & 130 & 240 & 40 & 17 & 4 & 5 \\
FA-Phe-Leu-OH & 210 & 370 & 52 & 33 & 3 & 11 \\
FA-Phe-Phe-OH & 330 & 200 & 16 & 13 & 0.6 & 15 \\
\hline
\end{tabular}


Table VII. Relative $k_{\text {ral }} / K_{2}$ values for hydrolysis of substrates with blocked C-terminal with CPD-Y and derivatives at position 398.

\begin{tabular}{lccccrrr}
\hline Substrate & CPD-Y & $\begin{array}{l}\text { MeS-Cys- } \\
\text { CPD-Y }\end{array}$ & $\begin{array}{l}\text { Eta-Cys- } \\
\text { CPD-Y }\end{array}$ & $\begin{array}{l}\text { PrS-Cys- } \\
\text { CPD-Y }\end{array}$ & $\begin{array}{l}\text { BzlS-Cys- } \\
\text { CPD-Y }\end{array}$ & $\begin{array}{l}\text { Pha-Cys- } \\
\text { CPD-Y }\end{array}$ \\
\hline FA-Phe-OMe & 100 & 50 & 100 & 210 & 390 & 230 \\
FA-Ala-OBzl & 100 & 100 & 11 & 59 & 6 & 15 \\
\hline FA-Phe-NH & 100 & 71 & 150 & 170 & 690 & 270 \\
FA-Phe-Gly-NH & 100 & 88 & 100 & 250 & 100 & 190 \\
FA-Phe-Val-NH & 100 & 26 & 7 & 6 & 5 & 10 \\
\hline
\end{tabular}

MeS-Cys-CPD-Y. The non-bulky nucleophile $\mathrm{H}-\mathrm{Gly}-\mathrm{NH}_{2}$ can be tolerated in the $\mathrm{S}_{1}$ binding site of CPD-Y, MeS-Cys-CPD-Y and PrS-CysCPD-Y, but not in BzlS-Cys-CPD-Y. Thus, in accordance with the results of the kinetic studies, it is conceivable that the fraction of aminolysis is affected by the combined size of the group occupying position 398 and the added nucleophile.

Using free amino acids as nucleophiles the fractions of aminolysis observed with MeS-CysCPD-Y were of similar magnitude to or exceeded those observed with CPD-Y, and this demonstrates, that enzyme derivatives obtained by genetic and/or chemical methods in some cases with advantage can be utilized in peptide synthesis.

Cys-CPD-Y exhibits reduced stability at $\mathrm{pH}$ 10.0 compared to the chemically modified derivatives and wildtype CPD-Y. However, at $\mathrm{pH}$ 6.5 Cys-CPD-Y is significantly more stable than CPD-Y, even at elevated temperatures. Under these conditions the stabilities of the chemical derivatives are comparable to that of wildtype CPD-Y. This suggests that the instability of Cys-CPD-Y is associated with the ability of a thiol group to ionize at high $\mathrm{pH}$ values, i.e. the $\mathrm{pK}_{\mathrm{a}}$ value of a $-\mathrm{SH}$ group is usually around 8.5. The high stability of Cys-CPD-Y at neutral $\mathrm{pH}$ could be due to the ability of the thiol group of Cys-398 to enter into a hydrogen bond, or alternatively, it could be associated with a conformational change at the $S_{1}^{\prime}$ binding site of Cys-CPD-Y (see beginning of this section). Although the thioalkylated derivatives are less stable than Cys-CPD-Y they are nevertheless more stable than the derivatives without disul- fide suggesting that this structural feature has a stabilizing effect. This hypothesis is supported by the fact that AeS-Cys-CPD-Y is much more stable than the structurally and enzymatically similar Arg-CPD-Y and Ama-Met-CPD-Y ( 1 , 7).

The data presented above demonstrate that site-directed mutagenesis and chemical modifications successfully can be combined to increase the number of substitutions possible at an important position of the enzyme. In addition, this approach can be applied to incorporate various spectrochemical probes, e.g ${ }^{13} \mathrm{C}$ and fluoroscence, allowing studies of the surrounding parts in the protein. A cysteinyl residue at an appropriate location in a protein also improves the possibilities for introduction of cross links, thus providing a method for determination of inter-residue distances and relationships between various domains.

\section{ACKNOWLEDGEMENTS}

Professor MORTEN KIELland-BrandT is thanked for invaluable advice during this work, and Professors Martin OTtesen and KLAUS BoCK and Dr. IB SVENDSEN for carefully reading the manuscript. Mss LILLIAN ABILDGAARD and SUSANNE EWALD are acknowledged for excellent technical assistance. 


\section{REFERENCES}

1. BECH, L.M., J. NIELSEN, J.R. WINTHER, M.C. KIELLAND-BRANDT \& $\mathrm{K}$ BREDDAM: Mutational replacement of methionine by arginine in the $S_{1}$ s substrate binding site of yeast carboxypeptidase. Carlsberg Res. Commun. 51, 459-465 (1985)

2. BREDDAM, K, F. WidMER \& J.T. JOHANSEN: Carboxypeptidase $Y$ catalysed transpeptidations and enzymatic peptide synthesis. Carlsberg Res. Commun. 45, 237-247 (1980)

3. BRedDAM, K: Modification of the single sulfhydryl group in carboxypeptidase $Y$ with mercurials. Influence on enzyme specificity. Carlsberg Res. Commun. 48, 9-19 (1983)

4. BREDDAM, K, S. SøRENSEN \& M. OTTESEN: Isolation of a carboxypeptidase from malted barley by affinity chromatography. Carlsberg Res. Commun. 48, 217-230 (1983)

5. BREDDAM, $K$ \& $M$. OTtESEN: Influence of guanidine derivatives on the specificity of malt carboxypeptidase. Carlsberg Res. Commun 48, 573-582 (1983)

6. BREDDAM, K. \& M. OTTESEN: Malt carboxypeptidase catalysed aminolysis reactions. Carlsberg Res. Commun. 49, 473-481 (1984)

7. BREDDAM, K: Chemically modified carboxypeptidase $Y$ with increased amidase activity. Carlsberg Res. Commun. 49, 535-554 (1984)

8. BREDDAM, $\mathrm{K}$ : Modification of amino acid residues in the $S_{1}$ binding site of carboxypeptidase $Y$. Carlsberg Res. Commun. 49, 627-638 (1984)

9. BREDDAM, K \& I. SVENDSEN: Identification of methionyl and cysteinyl residues in the substrate binding site of carboxypeptidase Y. Carlsberg Res. Commun. 49, 639-645 (1984)

10. BREDDAM K \& A. KANSTRUP: Cyanylation of the single sulfhydryl group in carboxypeptidase $Y$ with cyanogen bromide. Carlsberg Res. Commun. 52, 65-71 (1987)

11. BRUICE, T.W. \& G.L. KeNYON: Novel alkyl alkanethiolsulfonate sulfhydryl reagents. Modification of derivatives of L-cysteine. J. Prot. Chem. 1, 47-58 (1982)

12. JohANSEN, J.T., K. BREDDAM \& M. OTTESEN: Isolation of carboxypeptidase $Y$ by affinity chromatography. Carlsberg Res. Commun. 41, 1-14 (1976)

13. KUNKEL, T.A.: Rapid and efficient site-specific mutagenesis without phenotypic selection. Proc. Natl. Acad. Sci. USA 82, 488-492 (1985)

14. Messing, J.: A multi-purpose cloning system based on the single-stranded DNA bacteriophage M13. Recombinant DNA Tech. Bull., NIH publication No. 79-99, 2, 43-48 (1979)

15. Murray, N.E., W.J. Brammer \& K MURray: Lambdoid phages that simplify recovery of in vitro recombinants. Mol. Gen. Genet. 150, 53-61 (1977)

16. RIORDAN, J.F. \& B.L. VALIE: Reactions with Nethylmaleimid and p-mercurybenzoate. Meth. Enzymol. 25, 449-456 (1952)

17. SCHeChTER, I. \& A. Berger: On the size of the active site of proteases. I. Papain. Biochem. Biophys. Res. Commun. 27, 157-167 (1967)

18. SEGEL, l.: Biochemical calculations. John Wiley \& Sons, New York, pp. 393-395 (1968)

19. SHAKed Z., R.P. SZAJEwSKI \& G.M. Whitesides: Rate of thiol-disulfide interchange reactions involving proteins and kinetic measurements of thiol $\mathrm{pK}$, values. Biochemistry 19, 4156-4166 (1980)

20. Weber, K, J.R. Pringle \& M. OSborne: Measurement of molecular weights by electrophoresis on SDS-acrylamide-gel. Methods Enzymol. 26, 3-27 (1972)

21. WINTHER.J.R.. M.C. KIELLAND.BRANDT \& K. BREDDAM: Increased hydrophobicity of the $S_{1}$ binding site in carboxypeptidase $\mathrm{Y}$ obtained by site-directed mutagenesis. Carlsberg Res. Commun. 50, 273-284 (1985)

22. ZOLLER. M.J. \& M. S.MITH: Oligonucleotide-directed mutagenesis of DNA fragments cloned into M13 vectors. Meth. Enzymol. 100, 468-500(1983) 